\title{
Os Laços entre a Literatura Jnfantil e a Competência Leitora na Narrativa da Revista Nova Escola
}

\author{
The Ties between Child Literature and Reading Competence \\ in the Narrative of Nova Escola Magazine
}

\author{
Lígia Beatriz Carvalho ALMEIDA * \\ Marcele TONELLI $* *$ \\ Pedro BERTI ***
}

Resumo: $\mathrm{O}$ artigo apresenta o resultado de uma investigação sobre o estímulo à apropriação da literatura infantil nas salas de aula, sob a ótica do jornalismo educacional. Delimitou-se como corpus de pesquisa a Revista Nova Escola, da qual se analisou dozes meses de publicação. A formação da competência leitora, obtida com a dedicação à leitura de textos mais densos como os textos literários, foi o foco temático por atender, simultaneamente, às finalidades educativas e às finalidades sociais do jornalismo. Os resultados apontaram que a ampla maioria das reportagens analisadas não contemplou a contextualização de informações que pudesse contribuir para o entendimento do professor sobre causas, conseqüências e políticas públicas envolvidas no desenvolvimento de tal competência.

Palavras-chave: Leitura; Literatura infantil; Jornalismo educacional.

\footnotetext{
* Mestre em Comunicação Midiática UNESP (2005). Doutoranda em Educação, UNESP-Marília. Docente da Universidade do Sagrado Coração. Contato: ligiabeatrizcarvalho@ig.com.br.

** Graduando de Comunicação Social - Habilitação em Jornalismo na Universidade do Sagrado Coração. Contato: marceletonelli@yahoo.com.br. *** Graduando em Comunicação Social - Habilitação em Jornalismo na Universidade do Sagrado Coração. Contato: pedro.berti@bol.com.br.
} 
Abstract: The article presents the results of a research about the stimulation of children's literature use in classrooms, from the perspective of education journalism. Nova Escola magazine was the corpus, from which twelve months of publication were analyzed. The subject was chosen because the improvement of reading competence meets simultaneously education purposes and social journalism purposes. Reading dense texts, such as the literary ones, is an effective way to gain this competence. Results showed that the vast majority of the articles studied did not contribute to teacher's comprehension about the causes, consequences and policies involved in the development of such competence.

Key-words: Reading; Children's literature; Education journalism.

\section{Introdução}

Este artigo resulta de um esforço para entender as práticas do jornalismo educacional, atividade que visa difundir e incentivar a educação por meio dos veículos de comunicação. Delimitou-se como corpus de estudo a Revista Nova Escola, periódico segmentado de grande circulação entre os professores brasileiros, ao qual eles recorrem, com frequência, em busca de referências de conteúdo e práticas pedagógicas. Pretendeu-se observar a linha editorial do veículo e, para tanto, optouse por estudar o tratamento dado a um tema específico: à literatura infantil. A escolha foi feita considerando que entre os principais objetivos da educação básica está a formação da competência leitora e entre os objetivos do jornalismo está a ampliação e qualificação da base de leitores. A literatura infantil é um importante recurso para alcançar ambos os objetivos.

A pesquisa investigou qual o grau de importância atribuído ao tema pelo veículo de comunicação, baseado na frequência com que ele foi abordado no período delimitado e na qualidade da abordagem. Analisou-se o discurso da revista sobre literatura infantil e as sugestões do periódico para a sua inserção nas salas de aula da educação básica. Para cumprir com os objetivos, foi necessário delimitar-se: o conceito de literatura infantil adotado pela Revista Nova Escola, a indicação de metodologias para trabalhar o texto literário em sala de aula, a 
procedência das informações usadas na produção dessas matérias e a qualidade das mesmas.

\section{Educação e imprensa}

No cerne das profissões de educador e de jornalista, está um mesmo objetivo: contribuir para elevar a qualidade de vida da população brasileira.

$\mathrm{O}$ artigo $\mathrm{V}$ do Plano Nacional de Educação afirma ser a Educação um "valor em si, requisito para o exercício pleno da cidadania, para o desenvolvimento humano e para a melhoria da qualidade de vida da população" (BRASIL, 2001). As Diretrizes Curriculares Nacionais para o Ensino Fundamental de nove anos reconhecem a centralidade da Educação para o desenvolvimento potencial humano que possibilitará "o exercício dos direitos civis, políticos, sociais e do direito à diferença, sendo ela mesma também um direito social, e possibilita a formação cidadã e o usufruto dos bens sociais e culturais" (BRASIL, 2010).

O Código de Ética dos jornalistas brasileiros, em seu capítulo II discorre sobre a conduta do profissional e no artigo terceiro afiança a natureza social da profissão. $\mathrm{O}$ artigo sexto, menciona, entre outros, ser dever da profissão: “defender os princípios constitucionais e legais, base do estado democrático de direito [...]; defender os direitos do cidadão, contribuindo para a promoção das garantias individuais e coletivas, em especial as das crianças, dos adolescentes, das mulheres, dos idosos, dos negros e das minorias" (FENAJ, 2011). A responsabilidade do jornalismo repousa sobre o fortalecimento dos laços entre informação e cidadania, que, segundo a Agência de Notícias dos Direitos da Infância (ANDI) resulta em "prática jornalística dedicada à contextualização das notícias fortalece a cidadania, pois contribui para que a população possa conhecer e reivindicar seus direitos - o que significa revigorar e ampliar o capital social" (ANDI, 2006, p. 13).

Uma das condições essenciais para a liberdade e o desenvolvimento é a competência leitora, que implica na capacidade de compreender, relacionar, comparar informações e situar-se criticamente diante do texto lido. Pesquisa do IBOPE, realizada em 
2005, revela que apenas $26 \%$ dos brasileiros têm competência leitora. ${ }^{1}$ Constatou-se no estudo que, $7 \%$ dos cidadãos brasileiros são analfabetos; $30 \%$ dos brasileiros leem títulos e frases, reconhecem uma informação bem explícita e têm dificuldades de se expressar por meio da escrita sendo, portanto, analfabetos funcionais; 37\% têm uma habilidade básica de leitura, sendo capazes de ler textos curtos e de localizar informações explícitas.

Alcançar a fluência na leitura é essencial. O hábito de leitura leva à aquisição da fluência. Considerado baixo na comparação com países europeus, o índice de leitura dos brasileiros é de 4,7 livros ${ }^{2}$ por ano. Pais e professores são tidos como os principais atores na formação desse hábito. No entanto, para a maior parte das crianças inexiste a figura de pais leitores e a escola se torna o único local de incentivo à leitura. Cabe ao professor, então, o importante papel de incentivar e orientar a leitura de textos literários. Ele deve selecionar os livros com os quais pretende trabalhar e a metodologia a ser utilizada.

Também para o jornalismo é importante a universalização do letramento. De acordo com Bucci, "a responsabilidade social do jornalismo passa por assumir o desafio editorial de expandir e qualificar a base de leitores de notícias, em meios impressos e eletrônicos" (BUCCI, 2007). Dois interesses se somam sob a bandeira levantada pelos jornalistas. São eles: ampliar a base de leitores para aumentar a circulação dos produtos jornalísticos e qualificar o leitor para que esse exija um jornalismo de qualidade e com isso assegure a realização profissional dos jornalistas, que poderão elaborar textos mais densos e comprometidos com o ideal democrático.

${ }^{1}$ Disponível em: <http://www.ibope.com.br/calandraWeb/servlet/ CalandraRedirect? te mp $=6 \&$ proj= PortalI B O PE $\&$ pub $=\mathrm{T} \&$ nome $=$ impressao $\& \mathrm{db}=$ caldb\&docid $=$ B941262A 8 DCE70FB 8325 72AE004E7131>. Acesso em: 14 mar. 2010.

${ }^{2}$ Conforme pesquisa "Retratos da Leitura no Brasil", desenvolvida pelo Instituto Pró-Livro (IPL) em 2007. Disponível em: < http:/ / www.prolivro.org.br/ipl/ publier4.0/dados/anexos/48.pdf>. Acesso em: 14 mar. 2010. 


\section{Relações entre literatura infantil e escola}

Literatura infantil é um objeto de estudo acadêmico-científico recente. No Brasil, a massa crítica sobre o campo de conhecimento começou a organizar-se no início do século XX. Desde então, trabalhase para elaborar um referencial histórico e teórico que norteie a produção literária, subsidie o trabalho do professor e a educação das crianças e jovens.

Três momentos marcaram a relação da criança com a literatura no Brasil. Inicialmente, não existia produção específica para ela. À época, a parcela de crianças alfabetizadas se interessava por alguns livros escritos para adultos e os elegia para leitura. Posteriormente, segundo Lajolo (2007, p. 21), com a implantação da Imprensa Régia, em 1808, surgiram os primeiros livros escritos para crianças. Eles eram, em sua maioria, traduções e adaptações de obras estrangeiras e refletiam a cultura européia. Paralelamente a esses, começaram a ser produzidos livros para serem utilizados especificamente na escola e com eles uma nova tendência: a de se usar o livro infantil como um veículo de formação moral (LOURENÇO FILHO, 1943, p.149). Despontou, então, o questionamento sobre uma possível diferenciação entre literatura escolar didática e literatura infantil. Decidiu-se, enfim, pela delimitação entre as duas, momento que marca uma nova fase. A literatura infantil passou a ser considerada aquela cujo maior compromisso fosse com a estética e a arte. Lajolo (2000) atribui a Monteiro Lobato o pioneirismo na produção literária infantil com temas genuinamente nacionais. Para a autora "com o Sítio do Pica-pau Amarelo, Monteiro Lobato inaugura a literatura infantil brasileira” (LAJOLO, 2000, p. 60).

Vale lembrar alguns fatos que contribuíram para que a literatura infantil se tornasse um campo de estudos. Falar sobre o tema só começou a fazer sentido a partir do momento em que se formulou o conceito de infância. Houve época em que criança era considerada tão somente um adulto em miniatura, "sem distinções morfológicas, sociais, psicológicas” (ARROYO, 1968, p.120) e assim sendo, não se justificava produção específica para ela. O conceito contemporâneo surge com a necessidade da consolidação da burguesia, enquanto classe social. Uma vez que o poder dessa classe era de natureza política, não derivando dos bens possuídos, para se legitimar precisava das instituições família 
e escola, o que fez com que o núcleo familiar se tornasse a "finalidade existencial do indivíduo, tendo como maior beneficiário a criança. A preservação da infância impõe-se enquanto valor e meta de vida" (LAJOLO e ZILBERMAN, 2007, p. 16). Além do mais, a figura da criança decifrando o texto de um livro, só pode surgir em consequência de alguns fatores: a consolidação da imprensa, a implantação de programas de alfabetização e a formação de um mercado consumidor, que deu sustentação para a produção e a circulação de livros em larga escala, com custo popular.

Mas, afinal, o que é literatura infantil? Para ser considerada literatura infantil poderia uma obra ter finalidade instrumental (alertar), utilitária (moldar), didática, ou teria que ser integralmente estética? Foi o embate teórico existente de 1940 até o fim daquele século.

Lourenço Filho (1943, p. 155-156) entendia literatura infantil como veículo artístico, por meio do qual se levariam ensinamentos para a criança. Cecília Meireles (1979), no final dos anos 1940, desconsiderava a perspectiva da produção, adotando a da apropriação. Para ela, literatura infantil era toda aquela que a criança, por sua livre e espontânea vontade, escolhia para ler, independente de a obra ter sido escrita especificamente para crianças. Como resultado, muitas obras originariamente destinadas ao público adulto poderiam ser consideradas, por Meireles, literatura infantil O sociólogo Fernando Azevedo (1952) abraçou a noção de literatura infantil como força criadora que permitiria a fantasia infantil transformar o real, não devendo servir para doutrinar o destinatário. Por outro lado, Arroyo (1968, p. 11-12) manifestava uma preocupação com os aspectos culturais. Para ele, literatura infantil poderia "significar realidade mais ampla, [...] ser em cada país considerada expressão geral de sua cultura, com profundas raízes no passado, portanto ligada aos sentimentos do povo, suas tradições e aspirações", assumindo a função de "transmissão geral da cultura”. Na década de 1980, Nelly Novaes Coelho (1984) sustentava que a natureza da literatura pertencia simultaneamente à literatura e à pedagogia. Já Lajolo, Zilberman (2007) e Perrotti (1986) vinculavam literatura infantil apenas à esteticidade, não admitindo compromissos com objetivos escolares.

A partir do século XXI parece haver um entendimento de que diversos fatores se somam para determinar a produção e a circulação 
da literatura infantil. Dessa forma, literatura infantil passa a ser considerada não só aquela produzida para crianças e nem somente aquela apropriada pelo público alvo. Deve ser um texto ficcional, o que não implica que tenha que ser exclusivamente estético. É, assim, um produto que resulta das tensões entre os diversos atores que operam na instância da enunciação: o escritor, o mercado editorial, as secretarias de educação, o professor, o teórico pesquisador, a escola e os pais, sendo denominada "a cadeia produtiva do livro" (ROSA, ODONE, 2007, p.192).

Em função da não valorização da leitura entre os brasileiros, o livro é considerado um produto caro, por isso o volume de vendas para o consumidor final não é expressivo. Os custos de impressão e a dinâmica de distribuição dos produtos literários inviabilizam o financiamento de uma publicação pelo próprio autor, que fica refém das editoras e de seus critérios mercadológicos. A compra de grandes tiragens de livros, destinados ao público infantil, tem sido realizada pelo governo federal para distribuição nas escolas. ${ }^{3}$ Assim, o Estado tem grande influência na regulação do mercado produtivo. A academia presta sua contribuição na construção do conhecimento teórico, na formação dos professores e, muitas vezes, com efetiva contribuição para o desenho de políticas públicas de leitura, como o Plano Nacional de Livro e Leitura e o Programa Nacional de Biblioteca da Escola. A escola é o mais importante, quando não o único, local de incentivo à leitura infantil e de acesso gratuito da criança às obras literárias. $\mathrm{O}$ professor, e os pais com menor frequência, são os incentivadores diretos da leitura. O professor indica a leitura a ser realizada pelo aluno, que costuma estar disponível no acervo da escola e cobra o conteúdo em avaliação. Outro caminho, menos frequente, para que o livro seja

${ }^{3}$ De acordo com Silva e Morais (2011, p. 9), no segmento de educação infantil do PNBE/2008 foram inscritos 657 títulos de 99 editoras. Sessenta deles foram selecionados e adquiridos por $\mathrm{R} \$ 11.140 .653,20$ para envio a 85.179 instituições escolares brasileiras. O volume, que parece gigantesco, se encolhe no final da cadeia: a escola com até 150 alunos recebeu 20 títulos, aquelas com até 300 alunos, 40 livros e as com mais de 300, 60 livros. Os critérios de compra do MEC são também descritos na mesma página deste artigo. 
incorporado às salas de leitura nas escolas é a indicação de um professor e a aquisição com verbas próprias da escola. A criança, público alvo, não tem nenhuma participação no processo e a literatura, que deveria ser para ela fruição, adquire contornos de obrigação, tendo, assim, grande chance de ser repudiada.

\section{Desenvolvimento teórico do tema}

\subsection{A Revista Nova Escola}

A revista é uma publicação mensal de iniciativa da Fundação Victor Civita. Entrou em circulação em 1986, como prática de responsabilidade social do Grupo Abril, com a missão de "contribuir para a melhoria da Educação Básica - Educação Infantil, Ensino Fundamental e Ensino Médio" (REVISTA NOVA ESCOLA, 2010).

De acordo com seu sítio eletrônico, ${ }^{4}$ contava em 2008 com um total de um milhão, seiscentos e sessenta e nove mil leitores mensais. A formação de sua base de leitores foi incentivada em função de sua distribuição gratuita nas escolas, realizada por meio de parcerias firmadas com o governo federal e com as secretarias de educação, para os quais, afirma-se em seu sítio eletrônico, a assinatura sai a preço de custo. ${ }^{5}$ Uma pesquisa realizada pelo IBOPE ${ }^{6}$ com professores leitores de todo o país aponta sua relevância para os professores brasileiros. Averiguou que $86 \%$ deles acham que a revista é muito útil em sala de aula, 94\% acreditam que ela é compromissada com a educação e 74\% dizem aplicar as atividades de sala de aula publicadas na revista.

${ }^{4}$ Informação disponível em: <http://publiabril.com.br/marcas/59/revista/ informacoes-gerais $>$. Acesso em: 15 jan. 2010. O custo de assinatura anual é de $\mathrm{R} \$ 34,00$. No entanto, o mesmo valor é fixado para pessoas físicas, existindo pacotes promocionais para assinaturas de 2 a 3 anos e pagamento com parcelas mensais acessíveis à categoria.

${ }^{5}$ Disponível em <http://revistaescola.abril.com.br/avulsas/assinasecretarias.shtml>. Acesso em: 15 jan. 2010.

${ }^{6}$ Mais detalhes em <http://revistaescola.abril.com.br/avulsas/assinasecretarias.shtml>. Acesso em: 2 jan. 2010. 


\subsection{Análise de mídia: jornalismo, newsmaking e enquadramento}

Ao longo de várias décadas, diversos estudos foram elaborados sobre os efeitos dos meios de comunicação no funcionamento das sociedades modernas ou, em outras palavras, o poder do jornalismo em formatar o debate público através do modo como as notícias são construídas. Acredita-se que a produção dos textos jornalísticos apresenta conteúdos de natureza assimétrica e difusa em relação às reais demandas e interesses da sociedade civil.

Isso nos conduz ao conceito de newsmaking, definido como o conjunto de critérios que orientam as organizações jornalísticas na seleção dos acontecimentos, transformando um fato em notícia a partir do seu caráter relevante e de interesse público. Tais critérios valorativos são definidos em função da posição estratégica que cada organização ocupa no processo de produção das informações (WOLF, 1999, p. 188). Subjacentes a essa escala de valores existem fatores organizativos e burocráticos, relacionados à estruturação dos processos produtivos, como a seleção dos temas a serem abordados, a coleta de informações por meio de entrevistas e levantamento de dados, capazes de oferecer um parâmetro para atribuição de sentido às notícias:

As exigências organizativas e estruturais e as características técnicoexpressivas próprias de cada meio de comunicação de massa são elementos fundamentais para a determinação da reprodução da realidade social fornecida pelos mass media. Em todos estes estudos de casos específicos, fala-se sempre de "distorção inconsciente" (unwritting bias) ou de "estruturas inferênciais" (inferential structures) para indicar os critérios fundamentais que orientam a selecção dos acontecimentos e a sua apresentação. A diferença principal, no que respeita aos estudos sobre a produção de informação (newsmaking), é que estes não se referem à cobertura de um acontecimento particular, mas ao andamento normal da cobertura informativa por períodos prolongados (WOLF, 1999, p. 186).

Em geral, a mensagem jornalística não reflete em si os padrões utilizados pelos jornalistas na cobertura de determinados 
acontecimentos. Nessa perspectiva, a análise de enquadramento se constitui como uma ferramenta eficiente na identificação e análise dos assuntos e temas específicos existentes nos fatos noticiados e por isso optou-se por usá-la nesta investigação. As marcas textuais permitem concluir sobre o posicionamento do veículo e a natureza da sua atividade, que procura influir sobre o campo político, econômico e social, preservando e promovendo pontos de vista específicos que seguem linhas de ação política, cultural, ideológica ou econômica em disputa na esfera pública.

A análise do enquadramento é utilizada por pesquisadores para verificar os aspectos enfatizados por matérias jornalísticas. Goffman conceitua enquadramento como um conjunto de "marcos interpretativos construídos socialmente, que permitem às pessoas atribuírem sentidos aos acontecimentos e às situações sociais" (apud Soares 2006, p. 451). Entman, citado por Porto (2004), complementa essa visão sintetizando o enquadramento segundo as variáveis de seleção e saliência, sendo a primeira referente à etapa inicial da escolha do fato a ser registrado conforme os critérios jornalísticos de notícia, e a segunda, o tipo de enfoque que o jornalista deverá levar em consideração no momento em que estiver cobrindo um acontecimento e redigindo seu texto, fazendo com que ideias e opiniões se tornem salientes na matéria, em detrimento de outras menos ou inteiramente invisíveis, ou através da repetição, focalização e associações reforçadoras de palavras e imagens.

Com isso, os jornalistas passam a não somente identificar os temas que fazem parte dos acontecimentos, mas, também, a interpretar alguns elementos que possam, aparentemente, estar desconexos, acrescentado consistência e significado ao produto profissional e, fornecendo informação suplementar à percepção da realidade social ao público. Assim, os enquadramentos de notícias "são construídos por palavras, metáforas, conceitos, símbolos, ironias, imagens visuais, insinuações e sugestões da narrativa noticiosa" (TUCHMAN, 1993, p. 259). Conforme o grau de repetição, focalização e associações reforçadoras de palavras e imagens, o texto jornalístico fica mais discernível e memorável.

Para Hackett, a mensagem midiática pode desempenhar um importante papel político e ideológico, pelo fato de ele advir de uma 
matriz ideológica limitada. A matriz gera enquadramentos, constituídos por um conjunto de regras e conceitos, ativados e aplicados pelos jornalistas em seus relatos, porém isso não necessariamente ocorreria de forma consciente e nem mesmo visando deliberadamente a iludir ou manipular (HACKET'T apud PORTO, 2004, p. 76). As negociações de sentido ocorrem pelo confronto das informações recebidas nos enquadramentos feitos pela imprensa, com os valores preexistentes dos indivíduos e a opinião dos outros membros da coletividade (D'ANGELO apud SOARES 2006).

São definidos três paradigmas de enquadramento: "o paradigma cognitivo, cuja imagem é a de negociação; o crítico, cuja imagem é a de dominação; e o construcionista, cuja imagem é a de cooptação" (D'ANGELO apud SOARES 2006, p. 456). No paradigma cognitivo, a cobertura noticiosa se torna um enquadramento de acesso contínuo para o indivíduo, de modo que o procedimento pelo qual ele a interpreta, estimula saberes prévios. O paradigma crítico parte da premissa de que os enquadramentos provêm de rotinas utilizadas pelos jornalistas para a captação de notícias. Nele, os enquadramentos dominam o noticiário e as audiências através das informações produzidas pelas esferas hegemônicas. Noparadigma construcionista, os jornalistas ocupam posições estratégicas no processo de produção das informações e são responsáveis pela criação de pacotes interpretativos, a partir das posições de fontes noticiosas, "a fim de refletir e acrescentar-se à cultura do assunto" (SOARES, 2006, p.457). Nesse processo, para o autor, “os enquadramentos constrangeriam a consciência política de indivíduos, opor-se-iam aos objetivos dos grupos ligados a movimentos sociais; estabeleceriam parâmetros para os debates políticos, não necessariamente de acordo com procedimentos democráticos" (SOARES, 2006, p. 457).

\section{Pesquisa}

\subsection{Metodologia}

Para obter informações quantitativas e qualitativas capazes de revelar o tratamento dado pelo periódico ao tema literatura infantil, optou-se por trabalhar com uma abordagem metodológica que vem 
sendo empregada na investigação de textos jornalísticos, que considera o contexto descrito no item anterior. Essa metodologia requer a análise de conteúdo e de enquadramento, considerando os critérios descritos na sequência. Dessa forma, seria possível levantar dados sobre a frequência com que o assunto figuraria nas páginas do periódico, as opções conceituais, as fontes de consulta utilizadas na construção das matérias e a natureza das soluções oferecidas. O ferramental iria orientar e organizar a análise do extenso corpus, composto pelos doze exemplares da revista publicados entre janeiro e dezembro de 2008.

Para a análise de conteúdo, cada matéria foi caracterizada por meio de seis chaves de compreensão:

a) Fato em questão: indica a razão de a literatura infantil, ou a literatura, ser abordada nas reportagens. As matérias poderiam ser agrupadas em três categorias distintas. Na primeira, estariam àquelas abrangentes que incentivam a leitura de obras literárias, debatem conceitos e oferecem sugestões metodológicas para o trabalho em sala de aula. $\mathrm{Na}$ segunda, seriam alocadas matérias cujo foco não recaísse especificamente sobre o tema, mas que discutissem qualquer característica literária e sugerissem metodologias para trabalhá-las em sala de aula. Na terceira, permaneceriam aquelas em que os textos literários figurassem como mero pretexto para desenvolvimento da habilidade de leitura e escrita, ou de outras disciplinas escolares, sem envolver discussão específica sobre o tema;

b) Razões e consequências: implica verificar as conexões feitas pelo jornalista entre a prévia sugestão da matéria e a real aplicação na escola, ressaltando as divergências existentes entre teoria e prática;

c) Políticas públicas: analisa informações sobre políticas públicas educacionais, verificando mais precisamente a aplicabilidade e referências ao Plano Nacional de Educação (PNE), a Lei e Diretrizes e Bases da Educação (LDB), os Parâmetros Curriculares Nacionais (PCNs); e o Plano Nacional do Livro e da Leitura (PNL);

d) Atores sociais: tem como objetivo apurar as fontes que participam da matéria, tornando-as contextualizada em relação às suas diversas implicações; 
e) Dados e discussões específicas: verifica-se a presença de estatísticas, citações complementares à legislação atual, possíveis menções a temas correspondentes à área e informações que ampliam o contexto de compreensão do fato abordado;

f) Comportamento editorial: relacionado à análise do espaço editorial e gráfico ocupado pelas matérias, como posição do texto na página e presença de foto;

g) Conceito de literatura infantil: analisa pelas marcas textuais, quando existentes, qual o conceito de literatura e literatura infantil assumido na matéria.

As informações coletadas foram organizadas em fichas, de acordo com as chaves de compreensão.

Para a análise de enquadramento, foram utilizados os seguintes eixos:

a) Seleção de informações: apontam-se os aspectos da realidade enfocada, que foram selecionados pelo jornalista de maneira a compor o plano principal da matéria;

b) Ênfase de informações: na organização das matérias, pode ser percebida pelo ângulo da notícia adotado pelo jornalista, destacando-se em elementos como lide ${ }^{7}$ e título;

c) Exclusão de informações: refere-se aos dados que, embora sejam necessários para a contextualização do assunto em questão na matéria, não foram apurados pelo jornalista.

O software Microsoft Excel, foi utilizado na tabulação dos resultados obtidos. Nessa tabulação, as matérias foram organizadas de acordo com os critérios definidos. A primeira categoria, denominada "fato em questão", por exemplo, foi composta por três variáveis: preencheu-se " 1 " para as matérias cujo foco recaiu sobre a literatura e/ou incentivo à leitura de obras literárias, em reportagens abrangentes;

${ }^{7}$ Lide é a denominação dada à abertura de matéria jornalística tradicional. Precisa responder a seis perguntas básicas sobre o fato abordado: o que, quem, quando, onde, como e por quê. 
"2" para as matérias que discutiram características literárias, de forma fragmentada e superficial; e " 3 " se a literatura fosse utilizada como pretexto para aprendizagem da leitura e escrita ou de outras disciplinas escolares.

\subsection{Resultados}

Os dados coletados permitiram compreender as práticas do jornalismo educacional adotadas pelo periódico, bem como a sua abordagem específica à literatura infantil.

Do total de quatorze matérias que abordavam a temática, apenas uma enquadrou-se no primeiro grupo, tendo foco sobre literatura e incentivo à leitura de obras literárias; duas no segundo, abordando de forma fragmentada e superficial as características literárias; as outras onze foram classificadas no terceiro grupo. Verificou-se que ao todo, sete reportagens não trouxeram informações complementares ao assunto e cinco apenas mencionaram, de maneira superficial, informações que relacionavam o conteúdo didático sugerido pelo texto - novas formas de aprendizado relacionadas à literatura infantil - à sua aplicação no ambiente escolar.

Apenas uma matéria, intitulada "Machado, um clássico para todos", ampliou a abordagem à literatura, tendo sido elaborada por um motivo especial: as celebrações do "Ano Nacional Machado de Assis", escritor considerado o "maior nome da literatura nacional". A reportagem incentivou o uso das obras de Machado de Assis em séries iniciais do ensino fundamental. De um modo geral, diferenciou-se das outras pela diversidade de atores sociais presentes em sua contextualização e pela abordagem direta à literatura. Nela, evidenciase que as crianças devem participar ativamente como leitoras, fazendo perguntas e criando respostas sobre a trama e indicam-se caminhos para que o professor leve as crianças a identificar pistas narrativas existentes nos aspectos formais do texto. A matéria também elenca quais seriam esses aspectos. Ademais, há referência a algumas estratégias didáticas não adequadas por sugerirem a utilização do texto literário apenas como instrumento para o ensino de gramática ou por recomendarem a aplicação de testes após a leitura de um título, para forçar o aluno a ler. Entretanto, no texto identifica-se a inexistência de 
experiências e sugestões de trabalho com parte do público indicado pela reportagem, ou seja, o texto afirma que é possível trabalhar com Machado de Assis a partir do $3^{\circ}$ ano do ensino fundamental, porém não indica experiências e nem oferece sugestões para cumprir especificamente este objetivo.

Sobre a análise do segundo grupo de reportagens, que discutem de maneira fragmentada e superficial as características da Literatura Infantil, a matéria "Mais do que Letras", por exemplo, apresenta uma sequência didática em que apenas sugere dinâmicas de aplicação de diferentes gêneros literários com alunos de $1^{\mathrm{a}}$ a $2^{\mathrm{a}}$ séries e indica alguns títulos de contos, produzidos em diferentes países e épocas, para realização de práticas que estimulem o hábito da leitura e escrita nos alunos de $3^{\mathrm{a}}$ a $4^{\mathrm{a}}$ série do ensino fundamental, no entanto, o texto não traz esclarecimentos específicos sobre os conceitos a serem utilizados para análise dos textos literários, como: elementos que compõe um texto, peculiaridades de textos produzidos em diversos países, papel de personagens, caracterização de cenários, análise de elementos linguísticos, gêneros, diferenças entre os orais e os escritos. A reportagem também não discute as dificuldades na aplicação prática da metodologia, em função de desafios como os diferentes estágios de nível de leitura e escrita de cada aluno na sala. De forma geral, o texto é caracterizado pela inexistência de informações relativas às categorias: dados, discussões específicas e políticas públicas.

Inserida no terceiro grupo, no qual a Literatura Infantil é apenas um pretexto para aprender ou ampliar a habilidade de leitura e escrita, a reportagem "Autores Mirins" expõe a experiência de um projeto didático desenvolvido na pré-escola que utilizou contos infantis como apoio à produção de atividades com o objetivo de desenvolver a capacidade de produção textual nos alunos. O texto não discutiu as características literárias, não abordou as dificuldades encontradas na aplicação da metodologia, além de não ter consultado de maneira suficiente os atores sociais competentes. Em linhas gerais, a matéria não foi contextualizada com dados, discussões específicas e nem fez menção a políticas públicas do setor.

Ainda sobre o universo das quatorze matérias analisadas, outro indicador de superficialidade está no fato de que apenas três delas contextualizaram o incentivo à literatura infantil no âmbito de políticas 
públicas, trazendo alguma informação sobre as instâncias do sistema educacional brasileiro. Cada matéria deveria ter aproveitado a oportunidade para esclarecer o leitor sobre as competências dessas esferas no que concerne ao desenvolvimento e acompanhamento de políticas públicas do setor. Afinal, elas é que são capazes de trazer resultados efetivos e precisam ser divulgadas. O educador, os pais, os alunos têm que saber a quem recorrer.

Em outra categoria de análise, denominada "políticas públicas", verificou-se que, das quatorze matérias da pesquisa, dez tiveram como uma das fontes consultadas professores e especialistas de educação, enquanto que apenas três procuraram coletar informações de representantes de entidades da sociedade civil como ONGs, sindicatos, associações e conselhos profissionais. Nenhuma consultou instâncias do poder público, como prefeituras ou secretarias de educação. Com relação à categoria “dados e discussões específicas” apenas duas matérias apresentaram dados e estatísticas que possibilitassem ampliar o contexto em que o fato foi tratado. Sobre a categoria "comportamento editorial", todas as reportagens analisadas tinham fotos em suas páginas de cobertura e apenas duas foram destaque de capa.

\section{Análise dos resultados}

Partindo da distinção entre as matérias que focaram a cobertura em conceitos abrangentes de literatura infantil, e aquelas que abordaram a temática em assuntos superficiais e fragmentados, identificou-se que a maioria das reportagens analisadas não privilegiou o uso de informações contextualizadas com a realidade do ensino, apresentando as implicações práticas entre a prévia sugestão da matéria - novas formas didáticas relacionadas à literatura infantil - e a sua real aplicação no ambiente escolar.

Fatores inerentes à atividade jornalística certamente contribuem para que não se alcance um melhor resultado. Os prazos e recursos para a produção das matérias são limitados e a formação dos jornalistas raramente enfoca a comunicação educativa, dificultando a elaboração de reportagens abrangentes, coerentes com a realidade dos professores. O jornalista que exerce suas funções nesse veículo educativo, muito provavelmente, por desconhecer o conceito de leitura infantil é incapaz 
de estabelecer conexões entre o tema e um dos objetivos de sua profissão, a qualificação da base de leitores.

É significativo observar que grande parte das reportagens analisadas não respeitou o critério de pluralidade de fontes, se limitando a consultar fontes estáveis, regulares e institucionais, principalmente aquelas ligadas ao universo de contatos da revista, isto é, membros da equipe de especialistas da Fundação Victor Civita. Em algumas matérias, observou-se a necessidade do enfoque ter sido complementado por informações adicionais sobre políticas públicas, carência atribuída à ausência de consulta às fontes oficiais, criando assim, uma espécie de vício na seleção editorial, a qual acaba não privilegiando a divulgação de dados importantes sobre o sistema educacional brasileiro. Assim sendo, dá-se vazão a formação de opiniões parciais, que não contemplam informações sobre causas, consequências e políticas públicas relacionadas aos fatos em questão.

Em muitas matérias são suprimidas informações que poderiam facilitar o aprimoramento metodológico. Vale citar como exemplo a matéria Ler épreservar, uma divulgação do Projeto Douradinho que pretende incentivar o hábito de leitura entre alunos da rede pública e fazer da literatura um instrumento de educação ambiental. O texto centra sua cobertura somente no projeto e na sua repercussão e dá excessivo destaque ao autor da obra de literatura infantil e aos viabilizadores do projeto, o governo brasileiro e uma organização italiana. No entanto, não há qualquer menção sobre a metodologia que deve ser empregada pelo docente para desenvolver a atividade com o livro na escola.

A lógica de inclusão da maior parte das matérias parece advir da seleção, entre os relatos de práticas didáticas encaminhados por professores, daqueles que se enquadram em critérios estabelecidos pela equipe de especialistas da Fundação Victor Civita. Dessa forma, o discurso da revista é um espelhamento e uma sublimação da prática dos professores. No corpus analisado, não há evidência de que a revista traga propostas próprias. Colocam-se em relevo as iniciativas didáticas consideradas apropriadas à cultura escolar brasileira e os professores que as protagonizaram, para servirem de referência à coletividade de professores. Entretanto, a revista parece não levar em conta a realidade de grande parte das escolas públicas brasileiras, com estrutura deficitária que gera a insatisfação dos profissionais quanto às condições de trabalho 
impostas pela política de gestão educacional. Via de regra, as salas se transformam em locais superlotados e de difícil trabalho, tornando mais dificultosa a inserção de novas práticas. Por outro lado, outra constatação advém: uma vez que as matérias espelham a prática nas escolas, a pesquisa realizada evidencia a não discussão, ou a não valorização da discussão, no cotidiano das escolas, sobre o conceito de literatura infantil e os critérios a serem utilizados para selecionar e indicar as obras que alimentarão o imaginário do educando.

Em grande parte das matérias, as metodologias foram indicadas de modo pouco aprofundado. A revista acaba, por vezes, contradizendo o seu próprio papel ao sublimar o sucesso das realizações dos professores, premiados pelo grupo empresarial gestor do veículo de comunicação, deixando passar ao largo a oportunidade de trazer sugestões complementares ou promover discussões conceituais. Questiona-se se é suficiente colocar em relevo as boas práticas, sem abordar as dificuldades vivenciadas e superadas pelos professores que as protagonizaram. A reflexão sobre as condições de vida desses profissionais e as dificuldades por ele enfrentadas permitiria entender que medidas seriam necessárias para que outros professores também pudessem obter bons resultados. Questiona-se se a média dos professores brasileiros dispõe da mesma condição daqueles citados pela revista, premiados justamente por se destacarem, seja por terem uma formação ou condição de vida diferenciada, seja por estarem em instituições em que a gestão e a infra-estrutura são peculiares. O veículo poderia promover um debate em busca da resposta do que seria necessário para que todos os professores tivessem o mesmo desempenho dos colegas premiados. A análise das dificuldades poderia apontar caminhos para a superação das mesmas pelos docentes, que compõem o público alvo da revista e, oferecer subsídios para que o Governo, cliente de peso da editora, pudesse formular novas políticas públicas que favorecessem a formação do hábito de leitura e a produção de obras de literatura infantil. 


\section{Referências}

ANDI. Jornalismo investigativo: Concurso Tim Lopes: um estudo de caso sobre a atuação da imprensa no enfrentamento da violência sexual contra crianças e adolescentes. Childhood Brasil. Brasília: ANDI, 2006.

ARROYO, Leonardo. Literatura infantil brasileira: ensaio de preliminares para a sua história e suas fontes. São Paulo: Melhoramentos, 1968.

AZEVEDO, Fernando. A literatura infantil numa perspectiva sociológica. In: AZEVEDO, Fernando. Sociologia, São Paulo, v. 14, p. 43-63, 1952.

Agendamento da política. In: RUBIM, A. A. C. (org). Comunicação epolítica: conceitos e abordagens. São Paulo: Unesp, 2004, p. 42-70.

BRASIL, Ministério da Educação. Lei ñ 10.172. Plano Nacional de Educação. Disponível em: <https://www.planalto.gov.br/ccivil_03/ leis/leis_2001/110172.htm>. Acesso em: 04 set. 2010.

- Resolução $C N E / C E B n^{\circ} 7$. Diretrizes Curriculares Nacionais para o ensino fundamental de nove anos. Disponível em: <http:// portal.mec.gov.br/index.php?option=com_content $\&$ view $=$ article $\&$ id $=12992$ : diretrizes-para-a-educacao-basica \&catid=323:orgaos-vinculados $>$. Acesso em: 16 jan. 2011.

BUCCI, Eugenio. A responsabilidade social do jornalismo passa por assumir o desafio editorial de expandir e qualificar a base de leitores de noticias, em meios impressos e eletrônicos. Disponível em: <http://www. observatoriodaimprensa.com.br/artigos.asp?cod=454IMQ002>. Acesso em: 18 jan. 2011.

COELHO, Nelly Novaes. A literatura infantil: história, teoria, análise. São Paulo: Quiron, 1984.

FENAJ. Código de Ética dos Jornalistas Brasileiros. Disponível em: < http:/ /www.fenaj.org.br/juridico.php?id=5\#docs > . Acesso em: 19 jan. 2011. 
LAJOLO, Marisa; ZILBERMAN, Regina. Literatura Infantil Brasileira. São Paulo: Ática, 2007.

. Monteiro Lobato: um brasileiro sob medida. São Paulo: Moderna, 2000.

LOURENÇO FILHO, Manoel Bergström. Como aperfeiçoar a literatura infantil. Revista Brasileira. Rio de Janeiro, v. 3, n. 7, p. 146-69, 1943.

MAGNANI, Maria do Rosário Mortatti. Leitura, Literatura e Escola: sobre a formação do gosto. São Paulo: Martins Fontes, 2001.

MEIRELES, Cecília. Problemas da literatura infantil. Brasília: Summus/ INL/MEC, 1979.

MORTATTI Maria do Rosário Longo. Leitura crítica da literatura infantil. Leitura: teoria \& prática. Ano 19, n. 36, p. 11-17, dez 2000.

PERROT'TI, Edmir. O texto sedutor na literatura infantil. São Paulo: Ícone, 1986.

PORTO, Mauro Pereira. Enquadramento da mídia e política. In: RUBIM, A. A. C. (org.) Comunicação e política: conceitos e abordagens. São Paulo: Unesp, 2004, p. 74-104.

REVISTA NOVA ESCOLA. Fundação Victor Civita: educação de qualidade. Disponível em: http://revistaescola.abril.com.br/fvc/pdf/ nossa_historia.pdf. Acesso em: 15 fev. 2010.

ROSA, Flávia G. Mota Garcia; ODDONE, Nanci. Políticas públicas para o livro, leitura e biblioteca. Ci. Inf., Brasília, v. 35, n. 3, p. 183-193, set./ dez. 2006. Disponível em: <http://www.oei.es/fomentolectura/ politicas_publicas_livro_leitura_biblioteca.pdf>. Acesso em: 18 jan. 2011.

SILVA, Bruna Lidiane Marques; MORAIS, Elaine Maria da Cunha. $A$ constituição de acervos de literatura infantil para bibliotecas escolares: a escola 
como mercado e as escolhas editoriais. Disponível: em <http:// www.anped.org.br/reunioes/31 ra/1 trabalho/GT07-4037-Int.pdf >. Acesso em: 18 jan. 2011.

SOARES, Murilo César. Análise de enquadramento. In: DUARTE, J.; BARROS, A. Métodos e técnicas de pesquisa em comunicação. São Paulo: Atlas, 2006, p. 450-465.

WOLF. Mauro. Teorias da comunicação. Lisboa: Presença, 1999. 